\title{
Assessing population viability while accounting for demographic and environmental uncertainty
}

\author{
Steffen Oppel, ${ }^{1,4}$ Geoff Hilton, ${ }^{1}$ Norman Ratcliffe, ${ }^{2}$ Calvin Fenton,${ }^{3}$ James Daley, ${ }^{3}$ Gerard Gray,${ }^{3}$ \\ Juliet Vickerr, ${ }^{1}$ and David GibBons ${ }^{1}$ \\ ${ }^{1}$ RSPB Centre for Conservation Science, Royal Society for the Protection of Birds, The Lodge, Sandy, \\ Bedfordshire 591920 L United Kingdom \\ ${ }^{2}$ British Antarctic Survey, Natural Environment Research Council, High Cross, Madingley Road, \\ Cambridge CB3 OET United Kingdom \\ ${ }^{3}$ Montserrat Department of the Environment, P.O. Box 272, Brades, Montserrat, West Indies
}

\begin{abstract}
Predicting the future trend and viability of populations is an essential task in ecology. Because many populations respond to changing environments, uncertainty surrounding environmental responses must be incorporated into population assessments. However, understanding the effects of environmental variation on population dynamics requires information on several important demographic parameters that are often difficult to estimate. Integrated population models facilitate the integration of time series data on population size and all existing demographic information from a species, allowing the estimation of demographic parameters for which limited or no empirical data exist. Although these models are ideal for assessments of population viability, they have so far not included environmental uncertainty. We incorporated environmental variation in an integrated population model to account for both demographic and environmental uncertainty in an assessment of population viability. In addition, we used this model to estimate true juvenile survival, an important demographic parameter for population dynamics that is difficult to estimate empirically. We applied this model to assess the past and future population trend of a rare island endemic songbird, the Montserrat Oriole Icterus oberi, which is threatened by volcanic activity. Montserrat Orioles experienced lower survival in years with volcanic ashfall, causing periodic population declines that were compensated by higher seasonal fecundity in years with high pre-breeding season rainfall. Due to the inclusion of both demographic and environmental uncertainty in the model, the estimated population growth rate in the immediate future was highly imprecise (95\% credible interval $0.844-1.105$ ), and the probability of extinction after three generations (in the year 2028) was low (2.1\%). This projection demonstrates that accounting for both demographic and environmental sources of uncertainty provides a more realistic assessment of the viability of populations under unknown future environmental conditions.
\end{abstract}

Key words: ashfall events; Bayesian analysis; environmental stochasticity; Icterus oberi; integrated population model; island endemics; juvenile survival; Lesser Antilles; Montserrat Oriole; population viability analysis; tropical forest; volcanic activity.

\section{INTRODUCTION}

A major challenge in ecology is to describe and predict how population trends vary under different environmental conditions. This task is becoming increasingly urgent, as global climate change leads to changes in temperature and rainfall patterns around the world, which may affect many populations (Both et al. 2009, van de Pol et al. 2010, Senapathi et al. 2011). Environmental perturbations or long-term climatic changes can affect several demographic parameters, and integrating these complex interactions to assess the viability of a population can be challenging (Katzner et

Manuscript received 22 April 2013; revised 3 December 2013; accepted 10 January 2014. Corresponding Editor: E. E. Crone.

${ }^{4}$ E-mail: steffen.oppel@rspb.org.uk al. 2006, Nadeem and Lele 2012). Matrix population models, the standard tool for the study of population dynamics (Morris et al. 2002), may not offer reliable population projections if environmental conditions in the future deviate from the conditions during which data were collected (Crone et al. 2013), or if unobservable demographic processes such as transience and immigration affect population dynamics (Ellis and Crone 2013). Incorporating the environmental drivers of demographic parameters and demographic processes such as immigration into population projections may therefore improve forecasts and strengthen the practical relevance of population viability assessments.

For rare species of conservation concern, there are often insufficient data to estimate all the demographic parameters required to understand the population-level effects of environmental variation (Morris et al. 2002, 
Reed et al. 2002). Pattern-oriented modeling uses patterns observed in nature, such as a time series of population abundances, to derive underlying ecological processes (Grimm et al. 1996, Wiegand et al. 2003). Integrated population models are an extension of pattern-oriented modeling that integrate time series data on the size of a population and demographic information from a species to quantitatively assess population dynamics and estimate demographic parameters more precisely than if estimated independently (Besbeas et al. 2004, 2005, Schaub et al. 2007, Schaub and Abadi 2011). Data on population size contain information about all underlying demographic processes of a population that affect its size (e.g., births, deaths, immigration, and emigration). Integrated population models use this information together with data on some demographic parameters, and therefore enable the estimation of demographic parameters for which no empirical data exist (Besbeas et al. 2004, Abadi et al. 2010b, Schaub et al. 2013). Because these parameters are estimated quantitatively by maximizing a joint likelihood, the uncertainty around all demographic parameters is formally incorporated in a single modeling framework. Integrated population models are therefore an ideal tool for population viability analyses because they account more realistically for the uncertainty in a dynamic population system (Kéry and Schaub 2012).

Integrated population models have been used for many populations with a variety of data sources (Besbeas et al. 2005, Schaub and Abadi 2011). So far, however, many applications of these novel and fairly complex models have focused on statistical developments (Abadi et al. 2010a, 2012, McCrea et al. 2010); there are relatively few studies that focused primarily on the ecology or conservation of the target species (Freeman and Crick 2003, Véran and Lebreton 2008, Schaub et al. 2012). To our knowledge, the incorporation of environmental variation to assess population viability via an integrated population model has not been attempted so far. Existing demographic projection models that assess the effects of future environmental scenarios on population trends and population viability often do not integrate the uncertainty around all demographic and environmental processes, and may thus lead to unrealistic predictions (Coulson et al. 2001), especially if there is uncertainty about how environmental conditions affect demographic parameters (Crone et al. 2013). Here, we incorporate environmental variation in an integrated population model to account for both environmental and demographic stochasticity in a single modeling framework to assess population viability.

Besides environmental uncertainty, future population projections often suffer from the fact that some demographic parameters are unknown. Population models are highly sensitive to the survival of individuals before first reproduction (Robinson et al. 2004, Clark and Martin 2007, Sim et al. 2011), but estimating the survival probability of pre-reproductive life stages is extremely challenging (Lande et al. 2003, Schaub et al. 2010). Survival before first reproduction often remains unknown, particularly for mobile animal species in which immature individuals disperse and are therefore difficult to observe or recapture in a given study area (Tarwater et al. 2011). Although new approaches have been developed to address the problem of permanent emigration in survival estimation (Gilroy et al. 2012, Schaub and Royle 2013), these approaches require sufficient spatially segregated data to estimate the parameters of a distribution function. We present a novel approach to estimating true juvenile survival probability for a mobile bird species from an integrated population model to incorporate this critical parameter into our assessment of future population viability.

To demonstrate the utility of the integrated population model, we assessed the future population viability of a critically endangered island endemic bird, the Montserrat Oriole (Icterus oberi; see Plate 1). This forest songbird may be particularly susceptible to extinction induced by stochastic environmental events due to an active volcano affecting the small range $(\sim 1400$ ha) of its global population. The species is therefore an ideal case study for integrating environmental conditions into the assessment of population viability. We used population survey data, nest monitoring and individual mark-resighting data and estimated environmental effects on fecundity and adult and juvenile survival. We drew future values of environmental variables from random distributions to simulate environmental stochasticity. The integrated population model thus allowed us to estimate population trend and viability of the Montserrat Oriole while accounting for both environmental and demographic uncertainty.

\section{Methods}

\section{Study area and study species}

Montserrat $\left(16^{\circ} 45^{\prime} \mathrm{N}, 62^{\circ} 12^{\prime} \mathrm{W}, 104 \mathrm{~km}^{2}\right)$ is a small volcanic island in the Lesser Antilles with three major hill ranges, of which the southernmost consists of an active volcano that began to erupt in 1995 (see Plate 1). This eruption destroyed the largest forest area on Montserrat at that time (Arendt et al. 1999), and today only a single large forest area remains in the Centre Hills (1100 ha, maximum elevation $737 \mathrm{~m}$ above sea level). The Centre Hills are mostly covered in tropical moist broadleaf forest and currently host the majority of the global population of Montserrat Orioles (Allcorn et al. 2012, Oppel et al. 2014). The Centre Hills forest is $8 \mathrm{~km}$ north of the active volcano and is unlikely to be destroyed by pyroclastic flows. However, the South Soufriere Hills volcano is a typical stratovolcano that gradually accumulates magma in a volcanic dome until the dome collapses. Lava dome collapses produce large quantities of volcanic ash that can fall upon the entire Centre Hills area, depending on wind conditions (Scientific Advisory Committee 2011). 
Montserrat lies at the northern edge of the Intertropical Convergence Zone (ITCZ), which undergoes a pronounced seasonal cycle. As a consequence of this cyclicity, Montserrat experiences a rainfall season from April to November, with a relatively dry period from late November to the end of March (Barclay et al. 2006). The breeding season of Montserrat Orioles coincides with the wet season and generally lasts from late March until early September (Allcorn et al. 2012).

The Montserrat Oriole population comprises $\sim 700-$ 1000 individuals (Hilton et al. 2003, Oppel et al. 2014), and shows annual fluctuations in adult survival (Allcorn et al. 2012) and seasonal fecundity (Oppel et al. 2013). The species is highly territorial and inhabits rugged, mountainous forest habitat, where adults remain in their territories year-round.

\section{Demographic data}

Population monitoring data.-Montserrat Orioles were monitored by the Montserrat Department of Environment between 2000 and 2013, using 10-min point counts. We used the total number of orioles counted in each year at 50 survey points that were randomly distributed throughout the Centre Hills and were all at least $200 \mathrm{~m}$ apart. Further details about the annual monitoring procedures have been described in detail elsewhere (Hilton et al. 2003, Dalsgaard et al. 2007, Oppel et al. 2014).

Banding and resighting of adult birds.-Between 2000 and 2005, 81 adult and 187 fledgling Montserrat Orioles were marked with unique color-band combinations and resightings were recorded every year during the breeding season (Allcorn et al. 2012). We considered each breeding season as a separate encounter occasion to estimate annual survival probabilities for the period 2000-2005, following a previous analysis of this data set (Allcorn et al. 2012). Although adult Montserrat Orioles are territorial and highly site faithful, juvenile Montserrat Orioles disperse outside the study area; resighting data for juvenile birds are heavily influenced by local emigration (Allcorn et al. 2012).

Annual productivity.-Between 2001 and 2005, we studied annual fecundity by intensive monitoring of 42 breeding pairs, following nest finding and monitoring procedures described in detail elsewhere (Allcorn et al. 2012). The Montserrat Oriole is a multi-brooded species with a mean clutch size of three eggs, and annual fecundity is frequently the outcome of more than one successful brood. We observed pairs over the entire breeding season, and our measure of annual fecundity is the total number of fledglings that a pair raised from all clutches that were initiated in a season (Allcorn et al. 2012, Oppel et al. 2013).

\section{Environmental data}

We obtained rainfall data for the years 2000-2013 from a meteorological station that was operated continuously by the Montserrat Water Authority and was located adjacent to the western margin of the Centre Hills forest. We used two different temporal integrations of rainfall data each year to relate rainfall amounts to annual survival and annual fecundity, respectively. For annual survival, we considered the rainfall between breeding seasons, because rainfall during the nonbreeding period can affect food abundance and thus survival of songbirds in tropical environments (Szep 1995, Studds and Marra 2007). We therefore related annual survival to the sum of rainfall between September and March in the following year (eight months; hereafter, "winter rainfall"). For annual fecundity, we used the amount of rainfall between January and March (three months, hereafter: "pre-breeding rainfall"), because Montserrat Oriole fecundity increases with pre-breeding rainfall (Oppel et al. 2013).

We used a binary variable for the occurrence of heavy ashfall following three major volcanic dome collapses that occurred on 29 July 2001, on 12-13 July 2003, and on 11 February 2010. Another large dome collapse on 20 March 2000 had less influence on our study area because the ash cloud drifted east-south-eastward off the island (Carn et al. 2004). Although many other forms of volcanic activity occur on Montserrat (e.g., lava flows, magmatic explosions, earthquakes, rockfalls), these have not affected the Montserrat Oriole in the Centre Hills and are therefore not considered to affect the population during our study period.

\section{Integrated population model}

Our integrated population model was based on previous developments that linked population survey data with key demographic parameters (Besbeas et al. 2004, 2005, Schaub et al. 2007, Schaub and Abadi 2011, Kéry and Schaub 2012). We utilized the information contained in the survey data to estimate demographic parameters for which no empirical data existed (local immigration rate and true juvenile survival probability), and extended existing integrated population models by incorporating two environmental variables to explain and predict annual fluctuations in Montserrat Oriole abundance.

General structure and model fitting.-The integrated population model was constructed with two age classes, juveniles and adults, and we assumed that the sex ratio at hatching was 0.5 . Although some orioles may exhibit delayed maturity (Pleasants 1993, Jaramillo and Burke 1999), most female orioles of species for which data are available start breeding at the age of one year (Pleasants and Albano 2001, Flood et al. 2002, Werner et al. 2007), and we therefore assumed that all females started breeding at the age of one year.

We decomposed population dynamics into a state process that was described by adult and juvenile survival probability, annual fecundity, and local immigration. The state process was linked to the survey data via an observation process that accounted for the imperfect detection process during bird surveys. We used a 
hierarchical state-space model to decompose the observed time series of Montserrat Oriole point count data into a population process and an observation error component (de Valpine 2003, Clark and Bjørnstad 2004, Kéry and Schaub 2012). To estimate local adult and juvenile survival probabilities from individual capturerecapture data, we used Cormack-Jolly-Seber openpopulation live-recapture models. Fecundity was defined as the number of fledglings raised per mature female in each year, and was assumed to follow a Poisson distribution constrained by the number of observed pairs in each year.

We used a Leslie matrix to describe the transition probabilities of juveniles and adults from one year to the next and estimated those transition probabilities with the parameters for survival and fecundity. We assumed that annual survival during the first year of life (juvenile survival) was different from annual survival for birds that were older than 1 year (adult survival), but responded similarly to environmental variation, as we will discuss. To account for demographic stochasticity, we described the change of adult and juvenile population segments with a binomial and a Poisson distribution, respectively.

Because juveniles disperse from the study area into inaccessible areas of the Centre Hills forest, the estimate of juvenile survival derived from mark-resighting data does not account for birds that emigrate and persist in the population surrounding our study area. Similarly, birds from inaccessible areas in the Centre Hills can immigrate into our study area and supplement the existing adult breeding population. Because adults are extremely site faithful and disperse very little (Allcorn et al. 2012), we assumed that immigrants are birds in their second year of life. We estimated immigration rate following established approaches that estimate immigration from the trajectory of population size in the study area and capture-recapture data (Abadi et al. $2010 b$, Schaub et al. 2010, 2012). We used these estimates to infer true juvenile survival, because the species is endemic to Montserrat and immigrants can only be derived from inaccessible parts of the same population. We estimated true juvenile survival in year $t$ as the sum of locally surviving 1 -year-old birds and immigrants in year $t+1$ divided by the number of fledglings produced in year $t$.

We fitted the integrated population model using a Bayesian approach to combine the joint likelihood with prior probability distributions of the parameters to draw inferences about all demographic parameters (Schaub et al. 2007, 2010, Kéry and Schaub 2012). We ran three Markov chains each with 200000 iterations and discarded the first 100000 iterations. From the remaining iterations, we only used every sixth iteration for inference, and we tested for convergence using the Gelman-Rubin diagnostic (Brooks and Gelman 1998). To calculate the posterior distributions of the parameters of interest, we used Markov chain Monte Carlo
(MCMC) simulations implemented in program WinBUGS (Lunn et al. 2000) called from R 3.0.0 (R Development Core Team 2010) via the package R2WinBUGS (Sturtz et al. 2005). The R and WinBUGS code for the model is presented in the Supplement.

Prior distributions for demographic parameters.-One advantage of a Bayesian formulation of the integrated population model is the opportunity to use existing information to constrain demographic parameter estimates. We chose informative priors for the regression parameter of pre-breeding rainfall on fecundity (Oppel et al. 2013), and for adult survival and resighting probabilities (Allcorn et al. 2012). Although juvenile survival probability has never been estimated in the wild population of Montserrat Orioles, information from 152 captive-bred birds indicated that juvenile survival (0.60) was only $66 \%$ of adult survival in captivity (adult survival $=0.91$; data courtesy of Jersey Zoo, UK). We therefore used an informative prior that reflected the lower expected juvenile survival of Montserrat Orioles in the wild. For the remaining parameters, we used vague normal priors truncated to positive values for the initial age-specific population sizes.

Environmental variables and model selection.-The Montserrat Oriole population experiences large annual variations in rainfall, which affect the birds' fecundity (Oppel et al. 2013), and might also affect adult survival probabilities, which varied substantially among years (Allcorn et al. 2012). We constructed two separate models to examine whether this temporal variation in adult survival was best explained by winter rainfall (Dalsgaard et al. 2007), or by incidents of heavy volcanic ashfalls (Hilton et al. 2003, Marske et al. 2007). We selected the more parsimonious of these two integrated population models based on the value of the deviance information criterion (DIC; Spiegelhalter et al. 2002, Schaub et al. 2007), and used the more parsimonious model for inference and assessment of future population viability.

To account for environmental stochasticity in estimates of the Montserrat Oriole future population viability, we simulated environmental conditions from 2014 to 2028 within the integrated population model. Rainfall on Montserrat has been fairly stable over the past 110 years (Oppel et al. 2013), but the future distribution of rainfall on the island is unknown. We modeled rainfall as a random normal variable and estimated the mean and variance of this variable based on measured rainfall on Montserrat between 2000 and 2013. The eruption of the Soufriere Hills volcano on Montserrat has lasted $>17$ years so far, and is likely to continue for $>20$ years (Sparks and Aspinall 2004). We therefore assumed that the average annual probability of a volcanic ashfall event on Montserrat was $15 \%$ (Jaquet et al. 2006, Woo 2008, Scientific Advisory Committee 2011), and drew annual volcanic incidents from a binomial distribution with a probability of 0.15 . 


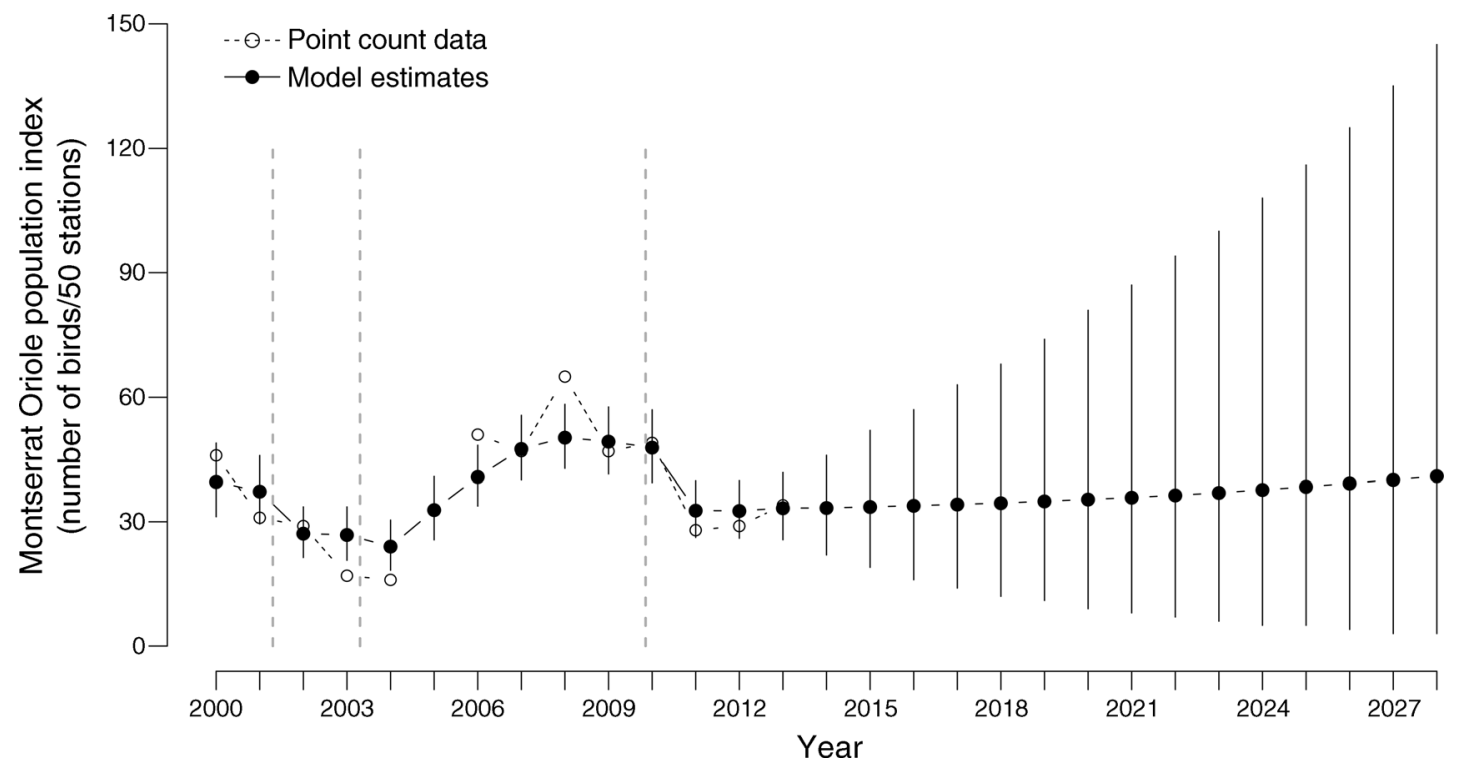

FIG. 1. Montserrat Oriole (Icterus oberi) population trajectory (with 95\% credible intervals) estimated from an integrated population model (solid circles) and observed at point count stations in the Centre Hills, Montserrat (open circles). The population index is the number of birds observed at 50 point count stations. Dashed vertical lines indicate major volcanic ashfall events in the Centre Hills.

Assessing population growth rate and viability.-The annual population growth rate was derived as the ratio of the number of females in year $t$ to the number of females in year $t+1$. The mean population growth rate from 2000 to 2013 was calculated as the geometric mean of all year-specific values, and we calculated a separate mean growth rate for the immediate future. To assess the extinction risk of Montserrat Orioles, we estimated population size for three generations (15 years) into the future, the time frame globally used by the International Union for Conservation of Nature (IUCN) to assess extinction risk. For each simulation, we used population sizes in 2028 in comparison with population sizes in 2013 to estimate projected population change, and compared these projected changes with IUCN criteria to assess the threat level for which the Montserrat Oriole qualified (Wanless et al. 2012). We considered the population to be functionally "extinct in the wild" if less than three birds remained in the Centre Hills study area, "critically endangered" if the projected population declined by more than $80 \%$, and "endangered" if the projected population declined at all. Projections indicating that the population would be stable or increase were classified as "vulnerable," given that the population is confined to $<15 \mathrm{~km}^{2}$ of forest (Oppel et al. 2014). We report the proportion of all simulations falling into each of the four IUCN categories.

\section{RESULTS}

The integrated population model that considered volcano effects on annual survival probability received more support from the data $(\mathrm{DIC}=231.3)$ than did the model that assumed that winter rainfall affected annual survival probability $(\mathrm{DIC}=242.9)$ or a model that considered constant annual survival $(\mathrm{DIC}=255.5)$. For inference, we therefore relied on the model that considered volcano effects. This model was able to replicate the major fluctuations in Montserrat Oriole abundance between 2000 and 2013 (Fig. 1). The parameter estimates confirmed that volcanic ashfall had a negative effect on adult survival $(b=-0.83 ; 95 \%$ credible interval $(\mathrm{CrI})=-1.42$ to -0.28$)$, and that fecundity increased with pre-breeding season rainfall $(b$ $=0.35$, CrI $=0.18-0.52$ ).

The annual adult survival probability (mean and $95 \%$ CrI) was $0.754(0.669-0.833)$ in years without volcanic ashfall, and $0.573(0.481-0.662)$ in years with volcanic ashfall. Estimates for true juvenile survival probability had lower precision, and mean estimates indicated that true juvenile survival was $\sim 69 \%$ of adult survival (Table 1). Local juvenile survival was very low ( 0.213 in years without ashfall, and 0.107 in years with ashfall), but local emigration of juveniles was balanced by an immigration component indicating that each year, $16.1 \%$ of the Montserrat Oriole population immigrated into the study area (Table 1).

The mean population growth rate between 2000 and 2013 was 0.987 (Table 1), and varied between 0.687 after a heavy volcanic incident in 2010 to 1.38 in a year (2004) with abundant pre-breeding season rainfall and high reproductive output (Fig. 1). Assuming that prebreeding season rainfall over the next 15 years would show similar mean and variability as between 2000 and 2013, and that the annual probability of a volcanic 
TABLE 1. Estimates of posterior mean, standard deviation (SD) and 95\% credible intervals of demographic parameters obtained from the integrated population model for the Montserrat Oriole (Icterus oberi).

\begin{tabular}{lccccc}
\hline \hline & & & \multicolumn{2}{c}{$95 \%$} \\
& & & \multicolumn{2}{c}{ credible limits } \\
\cline { 4 - 6 } \multicolumn{1}{c}{ Parameter } & Mean & SD & Lower & Upper \\
\hline Juvenile survival (volcano) & 0.372 & 0.128 & 0.154 & 0.651 \\
Adult survival (volcano) & 0.573 & 0.046 & 0.481 & 0.662 \\
Juvenile survival & 0.516 & 0.105 & 0.339 & 0.750 \\
Adult survival & 0.754 & 0.042 & 0.669 & 0.833 \\
Fecundity & 0.414 & 0.144 & 0.197 & 0.754 \\
Immigration & 0.161 & 0.054 & 0.062 & 0.272 \\
Past population growth rate & 0.987 & 0.013 & 0.961 & 1.013 \\
Future population growth rate & 0.990 & 0.065 & 0.844 & 1.105 \\
& & & &
\end{tabular}

Notes: Survival probabilities indexed by "volcano" refer to annual survival probabilities in years with volcanic ashfall. Past population growth rate refers to the period 2000-2013, future population growth rate refers to 2013-2028.

incident occurring would be $15 \%$, the predicted population growth rate between 2013 and 2028 was 0.990 (Table 1). The integration of both demographic and environmental stochasticity resulted in annually increasing uncertainty in future Montserrat Oriole population size (Fig. 1). The probability of extinction by 2028 was $2.1 \%$, and the probability of meeting the IUCN criteria for "critically endangered" was $4.7 \%$ (Fig. 2). There was an almost equal probability of classifying the Montserrat Oriole as "endangered" (47.4\%) or "vulnerable" $(45.8 \%)$, based on the projected future population growth rate.

\section{Discussion}

Our integrated population model accomplished two important objectives for assessing the population viability of a rare and threatened species: (1) combining population survey data and empirical data on fecundity and survival allowed us to estimate demographic parameters for which limited or no empirical data existed; and (2) accounting for both demographic and environmental uncertainty in a single framework provided more realistic confidence margins around predictions of future population viability. Population projection models that do not take environmental uncertainty into account may considerably underestimate the uncertainty surrounding future population sizes, which may lead to erroneous management decisions (Coulson et al. 2001, Reed et al. 2002, Doak et al. 2005, Crone et al. 2013). Our integrated population model thus overcomes one of the key deficiencies of population models, and will therefore provide a more reliable tool for conservation and management. Despite the considerable uncertainty surrounding the future population projections, our assessment of future population viability indicates that the Montserrat Oriole does not face a high and immediate risk of extinction under current environmental conditions.

Our model estimated that a small proportion of the surveyed Montserrat Oriole population in each year consisted of immigrants. Because the Montserrat Oriole is a single-island endemic species, immigration is most likely a result of birds originating from the same

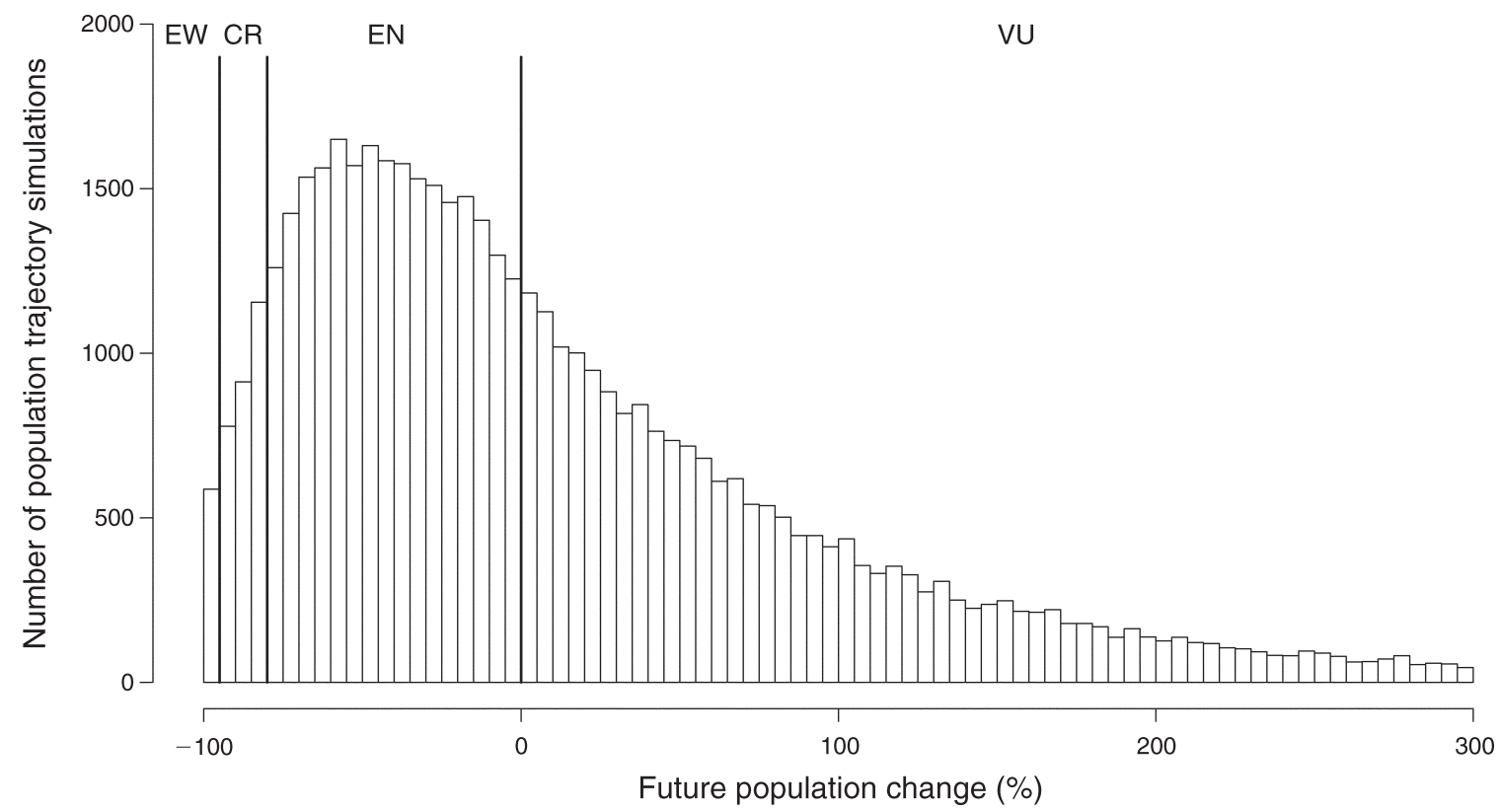

FIG. 2. Histogram of projected Montserrat Oriole population trajectories between 2013 and 2028, indicating the number of simulations that lead to different IUCN threat classifications: EW, extinct in the wild; CR, critically endangered; EN, endangered; VU, vulnerable. Note that IUCN threat categories are not solely based on the rate of population decline, but also consider the area of occupancy (http://www.iucnredlist.org/static/categories_criteria_3_1). 


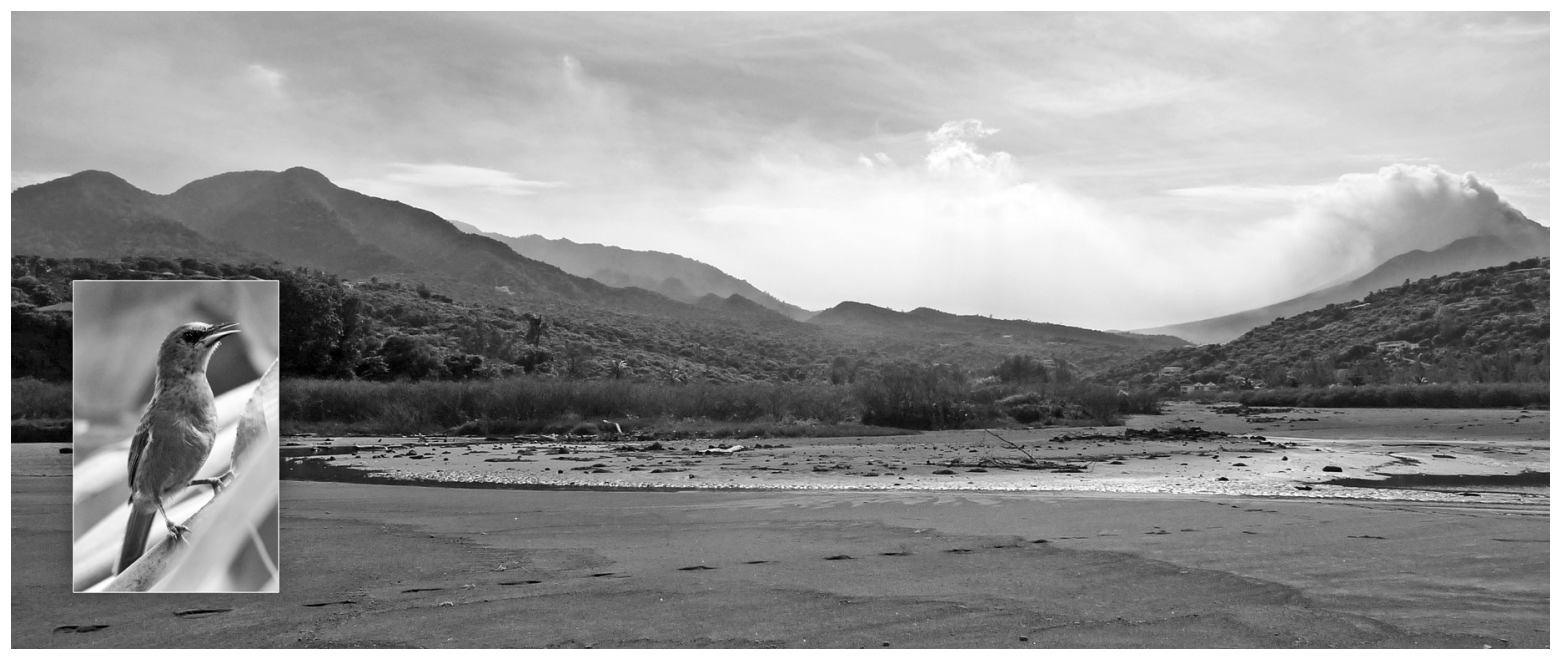

Plate 1. The Centre Hills forest (left) and the active Soufriere Hills volcano (right) on Montserrat. Inset: female Montserrat Oriole. Photo credits: main, S. Oppel; inset, Sorrel Jones.

population (Schaub et al. 2012). A second remnant population of the species exists in the South Soufriere Hills on Montserrat, $\sim 8 \mathrm{~km}$ from our study area (Oppel et al. 2014), but no information exists as to whether individuals move across unvegetated volcanic terrain between these two populations. We assumed that immigrants were immature individuals, and thus used the immigration rate to estimate true juvenile survival, an important demographic parameter to estimate population dynamics that is very difficult to obtain empirically (Gilroy et al. 2012).

Juvenile survival of tropical passerines is generally poorly known, but is sometimes assumed to be relatively high or even equal to adult survival because of the long parental care period of many tropical passerines (Covas et al. 2004, Ricklefs et al. 2011). Our estimates suggest that mean juvenile survival probability was around $69 \%$ of adult survival probability in Montserrat Orioles (Table 1), and thus similar to the empirical estimates of another tropical forest passerine (66\% of adult survival; Tarwater et al. 2011). Our model made the simplifying assumption that environmental conditions affected adult and juvenile survival equally, an assumption that may not be met (Robinson et al. 2004). Compared to the captive Montserrat Oriole population, where juvenile survival was $66 \%$ of adult survival, juvenile orioles in the wild do not seem to suffer proportionally more from environmental challenges because the ratio of juvenile to adult survival was similar in captivity and in the wild. We therefore believe that our simplified model is a reasonable approximation of the effects of volcanic activity on both juvenile and adult survival.

\section{Environmental effects on demography}

The population growth rate of the Montserrat Oriole depends on rainfall and the occurrence of stochastic ashfall events. Like many other tropical passerines, Montserrat Orioles have fairly high adult survival probabilities compared to temperate songbirds (Johnston et al. 1997, Ricklefs et al. 2011, Allcorn et al. 2012, Ruiz-Gutiérrez et al. 2012), and population dynamics are therefore sensitive to changes in adult survival (Sæther and Bakke 2000, Sibly and Hone 2002). Because volcanic activity strongly affected adult survival, episodic volcanic incidents led to intermittent population reductions in the Centre Hills. However, the positive effect of rainfall on fecundity enabled the Montserrat Oriole population to recover in years with sufficient prebreeding season rainfall. This result indicates that population dynamics in this species are a complex interaction of several demographic parameters that, in turn, are affected by different environmental conditions. The ability for rapid population recovery may be a useful trait for species endemic to islands of volcanic origin, where the process that led to the rise of the island and facilitated speciation would frequently affect populations of endemic species.

Due to the complex interactions of different environmental variables on the demography of the Montserrat Oriole, our estimates of future population size are surrounded by large uncertainty. Rainfall on Montserrat is highly variable (Barclay et al. 2006, Oppel et al. $2013 b$ ), and there are currently no reliable predictions of future rainfall trends. Likewise, the prediction of future volcanic incidents that will cause ashfall in the Centre Hills and thus affect the Montserrat Oriole is insufficiently precise for long-term demographic predictions (Scientific Advisory Committee 2011). Integrating this considerable environmental uncertainty in our population model led to increasingly imprecise predictions of future population size (Fig. 1). Although such imprecise predictions may appear to be unhelpful for long-term management, we feel that they capture the considerable 
uncertainty surrounding both the demographic parameters and the variable environment much more accurately than simpler models that do not take environmental uncertainty into account (Crone et al. 2013).

The dominant effect of rainfall on Montserrat Oriole demography was through enhancing fecundity, whereas annual variation in survival was better explained by volcanic incidents that released large amounts of volcanic ash. Although the increase in fecundity in years with higher rainfall is a consequence of larger clutch sizes and shorter renesting intervals (Oppel et al. 2013b), we currently do not understand the mechanism by which volcanic activity reduces annual survival probability of Montserrat Orioles. The periodic dome collapses of the South Soufriere Hills volcano that result in large volcanic ashfall in the Centre Hills may affect birds through a combination of direct and indirect effects (Butcher 1981). Volcanic ash may cause direct mortality or chronic lung disease (Horwell and Baxter 2006), or may induce chronic exposure to mercury (Tomiyasu et al. 2006), but ash may also reduce arthropod availability by covering soil and vegetation (Marske et al. 2007). Both chronic health effects and food shortages may increase mortality, and the Montserrat Oriole population trend thus depends to some extent on the frequency and severity of future volcanic activity.

In summary, our model provides reassurance that the Montserrat Oriole is currently not threatened with immediate extinction within three generations, but that annually varying environmental conditions can explain considerable annual fluctuations in the species' abundance. Our estimates of future population growth, which consider both demographic and environmental uncertainty, thus support a recent call to reassess the global conservation status of the Montserrat Oriole (Oppel et al. 2014). Based on the estimated probability of extinction in the near future, emergency conservation interventions for the Montserrat Oriole are probably unnecessary as long as the existing forest cover on Montserrat can be retained.

\section{ACKNOWLEDGMENTS}

We appreciate the support of the Montserrat Department of Environment and J. Millett in all aspects of the fieldwork on Montserrat. P. W. Atkinson, C. G. R. Bowden, M. Hulme, J. Madden, E. K. Mackley, J. Greenaway, J. Glenford, L. Martin, and J. Boatswain assisted with nest monitoring, capture, and observations of birds. We thank the Montserrat Water Authority for operating and sharing data of rainfall gauges. J. Barclay and A. Matthews provided valuable insights on rainfall measurements and rainfall patterns on Montserrat and their input is greatly appreciated. D. Jeggo, Durrell Wildlife Trust, and the Jersey Zoo provided the complete studbook of the captive Montserrat Oriole population. W. Aspinall, G. Thompson, C. Horwell and P. Cole shared their expertise on geophysics and volcanoes and provided us with much insight on volcanic events on Montserrat. S. Freeman, P. Besbeas, M. Schaub, M. Kéry, and F. Abadi shared their expertise and provided helpful advice on the construction and modification of the integrated population model. We thank A. Butler for help with WinBUGS, and P. Donald, R. Moreno, P. F. Quintana-
Ascencio, and two anonymous reviewers for constructive feedback on an earlier version of the manuscript.

\section{Literature Cited}

Abadi, F., O. Gimenez, R. Arlettaz, and M. Schaub. 2010a. An assessment of integrated population models: bias, accuracy, and violation of the assumption of independence. Ecology 91: $7-14$.

Abadi, F., O. Gimenez, H. Jakober, W. Stauber, R. Arlettaz, and M. Schaub. 2012. Estimating the strength of density dependence in the presence of observation errors using integrated population models. Ecological Modelling 242:1-9.

Abadi, F., O. Gimenez, B. Ullrich, R. Arlettaz, and M. Schaub. $2010 \mathrm{~b}$. Estimation of immigration rate using integrated population models. Journal of Applied Ecology 47:393-400.

Allcorn, R. I., G. M. Hilton, C. Fenton, P. W. Atkinson, C. G. R. Bowden, G. A. L. Gray, M. Hulme, J. Madden, E. K. Mackley, and S. Oppel. 2012. Demography and breeding ecology of the critically endangered Montserrat Oriole. Condor 114:227-235.

Arendt, W. J., D. W. Gibbons, and G. Gray. 1999. Status of the volcanically threatened Montserrat Oriole Icterus oberi and other forest birds in Montserrat, West Indies. Bird Conservation International 9:351-372.

Barclay, J., J. E. Johnstone, and A. J. Matthews. 2006. Meteorological monitoring of an active volcano: Implications for eruption prediction. Journal of Volcanology and Geothermal Research 150:339-358.

Besbeas, P., S. Freeman, and B. Morgan. 2005. The potential of integrated population modelling. Australian and New Zealand Journal of Statistics 47:35-48.

Besbeas, P., S. Freeman, B. Morgan, and E. Catchpole. 2004. Integrating mark-recapture-recovery and census data to estimate animal abundance and demographic parameters. Biometrics 58:540-547.

Both, C., M. van Asch, R. G. Bijlsma, A. B. van den Burg, and M. E. Visser. 2009. Climate change and unequal phenological changes across four trophic levels: constraints or adaptations? Journal of Animal Ecology 78:73-83.

Brooks, S. P., and A. Gelman. 1998. General methods for monitoring convergence of iterative simulations. Journal of Computational and Graphical Statistics 7:434-455.

Butcher, G. S. 1981. Northern Orioles disappear with Mt. St. Helens ashfall. Murrelet 62:15-16.

Carn, S. A., R. B. Watts, G. Thompson, and G. E. Norton. 2004. Anatomy of a lava dome collapse: the 20 March 2000 event at Soufrière Hills Volcano, Montserrat. Journal of Volcanology and Geothermal Research 131:241-264.

Clark, J. S., and O. N. Bjørnstad. 2004. Population time series: process variability, observation errors, missing values, lags, and hidden states. Ecology 85:3140-3150.

Clark, M. E., and T. E. Martin. 2007. Modeling tradeoffs in avian life history traits and consequences for population growth. Ecological Modelling 209:110-120.

Coulson, T., G. M. Mace, E. Hudson, and H. Possingham. 2001. The use and abuse of population viability analysis. Trends in Ecology and Evolution 16:219-221.

Covas, R., C. R. Brown, M. D. Anderson, M. B. Brown, and M. Brittingham. 2004. Juvenile and adult survival in the Sociable Weaver (Philetairus socius), a southern-temperate colonial cooperative breeder in Africa. Auk 121:1199-1207.

Crone, E. E., et al. 2013. Ability of matrix models to explain the past and predict the future of plant populations. Conservation Biology 27:968-978.

Dalsgaard, B., G. M. Hilton, G. A. L. Gray, L. Aymer, J. Boatswain, J. Daley, C. Fenton, J. Martin, L. Martin, and P. Murrain. 2007. Impacts of a volcanic eruption on the forest bird community of Montserrat, Lesser Antilles. Ibis 149:298312 . 
de Valpine, P. 2003. Better inferences from populationdynamics experiments using Monte Carlo state-space likelihood methods. Ecology 84:3064-3077.

Doak, D. F., K. Gross, and W. F. Morris. 2005. Understanding and predicting the effects of sparse data on demographic analyses. Ecology 86:1154-1163.

Ellis, M. M., and E. E. Crone. 2013. The role of transient dynamics in stochastic population growth for nine perennial plants. Ecology 94:1681-1686.

Flood, N. J., J. D. Rising, and T. Brush. 2002. Audubon's Oriole (Icterus graduacauda). Number 691 in A. Poole and F. Gill, editors. The birds of North America. American Ornithologists' Union and Philadelphia Academy of Natural Sciences, Philadelphia, Pennsylvania, USA.

Freeman, S., and H. Crick. 2003. The decline of the Spotted Flycatcher Muscicapa striata in the UK: an integrated population model. Ibis 145:400-412.

Gilroy, J. J., T. Virzi, R. L. Boulton, and J. L. Lockwood. 2012. A new approach to the "apparent survival" problem: estimating true survival rates from mark-recapture studies. Ecology 93:1509-1516.

Grimm, V., K. Frank, F. Jeltsch, R. Brandl, J. Uchmański, and C. Wissel. 1996. Pattern-oriented modelling in population ecology. Science of the Total Environment 183:151-166.

Hilton, G., P. Atkinson, G. Gray, W. Arendt, and D. Gibbons. 2003. Rapid decline of the volcanically threatened Montserrat oriole. Biological Conservation 111:79-89.

Horwell, C. J., and P. J. Baxter. 2006. The respiratory health hazards of volcanic ash: a review for volcanic risk mitigation. Bulletin of Volcanology 69:1-24.

Jaquet, O., R. Carniel, S. Sparks, G. Thompson, R. Namar, and M. Di Cecca. 2006. DEVIN: A forecasting approach using stochastic methods applied to the Soufriere Hills Volcano. Journal of Volcanology and Geothermal Research 153:97-111.

Jaramillo, A., and P. Burke. 1999. New World blackbirds: the icterids. Christopher Helm, London, UK.

Johnston, J. P., S. A. White, W. J. Peach, and R. D. Gregory. 1997. Survival rates of tropical and temperate passerines: a Trinidadian perspective. American Naturalist 150:771-789.

Katzner, T. E., E. A. Bragin, and E. Milner-Gulland. 2006. Modelling populations of long-lived birds of prey for conservation: A study of imperial eagles (Aquila heliaca) in Kazakhstan. Biological Conservation 132:322-335.

Kéry, M., and M. Schaub. 2012. Bayesian population analysis using WinBUGS. Academic Press, Oxford, UK.

Lande, R., S. Engen, and B. E. Sæther. 2003. Stochastic population dynamics in ecology and conservation. Oxford University Press, Oxford, UK.

Lunn, D. J., A. Thomas, N. Best, and D. Spiegelhalter. 2000. WinBUGS - a Bayesian modelling framework: concepts, structure, and extensibility. Statistics and Computing 10: 325-337.

Marske, K. A., M. A. Ivie, and G. M. Hilton. 2007. Effects of volcanic ash on the forest canopy insects of Montserrat, West Indies. Environmental Entomology 36:817-825.

McCrea, R. S., B. J. T. Morgan, O. Gimenez, P. Besbeas, J.-D. Lebreton, and T. Bregnballe. 2010. Multi-site integrated population modelling. Journal of Agricultural, Biological, and Environmental Statistics 15:539-561.

Morris, W. F., P. L. Bloch, B. R. Hudgens, L. C. Moyle, and J. R. Stinchcombe. 2002. Population viability analysis in endangered species recovery plans: past use and future improvements. Ecological Applications 12:708-712.

Nadeem, K., and S. R. Lele. 2012. Likelihood based population viability analysis in the presence of observation error. Oikos 121:1656-1664.

Oppel, S., A. Cassini, C. Fenton, J. Daley, and G. Gray. 2014. Population status and trend of the critically endangered Montserrat Oriole. Bird Conservation International 24:252261.
Oppel, S., G. M. Hilton, R. Allcorn, C. Fenton, A. J. Matthews, and D. Gibbons. 2013. The effects of rainfall on different components of seasonal fecundity in a tropical forest passerine. Ibis 155:464-475.

Pleasants, B. Y. 1993. Altamira Oriole (Icterus gularis). Number 56 in A. Poole and F. Gill, editors. The birds of North America. American Ornithologists' Union and Philadelphia Academy of Natural Sciences, Philadelphia, Pennsylvania, USA.

Pleasants, B. Y., and D. J. Albano. 2001. Hooded Oriole (Icterus cucullatus). Number 568 in A. Poole and F. Gill, editors. The birds of North America. American Ornithologists' Union and Philadelphia Academy of Natural Sciences, Philadelphia, Pennsylvania, USA.

R Development Core Team. 2010. R: A language and environment for statistical computing. R Foundation for Statistical Computing, Vienna, Austria. http://www. r-project.org/

Reed, J. M., L. S. Mills, J. B. Dunning, E. S. Menges, K. S. McKelvey, R. Frye, S. R. Beissinger, M.-C. Anstett, and P. Miller. 2002. Emerging issues in population viability analysis. Conservation Biology 16:7-19.

Ricklefs, R., T. Tsunekage, and R. Shea. 2011. Annual adult survival in several New World passerine birds based on age ratios in museum collections. Journal of Ornithology 152: 481-495.

Robinson, R. A., R. E. Green, S. R. Baillie, W. J. Peach, and D. L. Thomson. 2004. Demographic mechanisms of the population decline of the song thrush Turdus philomelos in Britain. Journal of Animal Ecology 73:670-682.

Ruiz-Gutiérrez, V., P. F. Doherty, Jr., E. Santana C., S. C. Martínez, J. Schondube, H. V. Munguía, and E. Iñigo-Elias. 2012. Survival of resident Neotropical birds: considerations for sampling and analysis based on 20 years of bird-banding efforts in Mexico. Auk 129:500-509.

Sæther, B.-E., and O. Bakke. 2000. Avian life history variation and contribution of demographic traits to the population growth rate. Ecology 81:642-653.

Schaub, M., and F. Abadi. 2011. Integrated population models: a novel analysis framework for deeper insights into population dynamics. Journal of Ornithology 152:227-237.

Schaub, M., A. Aebischer, O. Gimenez, S. Berger, and R. Arlettaz. 2010. Massive immigration balances high anthropogenic mortality in a stable eagle owl population: Lessons for conservation. Biological Conservation 143:1911-1918.

Schaub, M., O. Gimenez, A. Sierro, and R. Arlettaz. 2007. Use of integrated modeling to enhance estimates of population dynamics obtained from limited data. Conservation Biology 21:945-955.

Schaub, M., H. Jakober, and W. Stauber. 2013. Strong contribution of immigration to local population regulation: evidence from a migratory passerine. Ecology 94:1828-1838. Schaub, M., T. Reichlin, F. Abadi, M. Kéry, L. Jenni, and R. Arlettaz. 2012. The demographic drivers of local population dynamics in two rare migratory birds. Oecologia 168:97-108.

Schaub, M., and J. A. Royle. 2013. Estimating true instead of apparent survival using spatial Cormack-Jolly-Seber models. Methods in Ecology and Evolution, in press. http://dx.doi. org/10.1111/2041-210X.12134

Scientific Advisory Committee. 2011. Assessment of the hazards and risks associated with the Soufriere Hills Volcano, Montserrat. Fifteenth Report of the Scientific Advisory Committee on Montserrat Volcanic Activity. Montserrat Volcano Observatory, Montserrat.

Senapathi, D., M. A. C. Nicoll, C. Teplitsky, C. G. Jones, and K. Norris. 2011. Climate change and the risks associated with delayed breeding in a tropical wild bird population. Proceedings of the Royal Society B 278:3184-3190.

Sibly, R. M., and J. Hone. 2002. Population growth rate and its determinants: an overview. Philosophical Transactions of the Royal Society B 357:1153. 
Sim, I. M. W., G. W. Rebecca, S. C. Ludwig, M. C. Grant, and J. M. Reid. 2011. Characterizing demographic variation and contributions to population growth rate in a declining population. Journal of Animal Ecology 80:159-170.

Sparks, R. S. J., and W. P. Aspinall. 2004. Volcanic activity: Frontiers and challenges in forecasting, prediction and risk assessment. Pages 359-373 in R. S. J. Sparks and C. J. Hawkesworth, editors. State of the planet: Frontiers and challenges in geophysics. American Geophysical Union, Washington, D.C., USA.

Spiegelhalter, D. J., N. G. Best, B. P. Carlin, and A. Van Der Linde. 2002. Bayesian measures of model complexity and fit. Journal of the Royal Statistical Society B 64:583-639.

Studds, C. E., and P. P. Marra. 2007. Linking fluctuations in rainfall to nonbreeding season performance in a longdistance migratory bird, Setophaga ruticilla. Climate Research 35:115.

Sturtz, S., U. Ligges, and A. Gelman. 2005. R2WinBUGS: a package for running WinBUGS from R. Journal of Statistical Software 12:1-16.

Szep, T. 1995. Survival rates of Hungarian sand martins and their relationship with Sahel rainfall. Journal of Applied Statistics 22:891-904.

Tarwater, C. E., R. E. Ricklefs, J. D. Maddox, and J. D. Brawn. 2011. Pre-reproductive survival in a tropical bird and its implications for avian life histories. Ecology 92:12711281 .
Tomiyasu, T., M. Eguchi, H. Sakamoto, K. Anazawa, and R. Imura. 2006. Seasonal change and vertical movement of atmospheric mercury at Kagoshima City in relation with Sakurajima Volcano, Japan. Geochemical Journal 40:253263.

van de Pol, M., Y. Vindenes, B.-E. Sæther, S. Engen, B. J. Ens, K. Oosterbeek, and J. M. Tinbergen. 2010. Effects of climate change and variability on population dynamics in a longlived shorebird. Ecology 91:1192-1204.

Véran, S., and J.-D. Lebreton. 2008. The potential of integrated modelling in conservation biology: A case study of the blackfooted albatross (Phoebastria nigripes). Canadian Journal of Statistics 36:85-98.

Wanless, R. M., N. Ratcliffe, A. Angel, B. C. Bowie, K. Cita, G. M. Hilton, P. Kritzinger, P. G. Ryan, and M. Slabber. 2012. Predation of Atlantic Petrel chicks by house mice on Gough Island. Animal Conservation 15:472-479.

Werner, S. M., S. J. Hejl, and T. Brush. 2007. Breeding ecology of the Altamira Oriole in the lower Rio Grande Valley, Texas. Condor 109:907-919.

Wiegand, T., F. Jeltsch, I. Hanski, and V. Grimm. 2003. Using pattern-oriented modeling for revealing hidden information: a key for reconciling ecological theory and application. Oikos 100:209-222.

Woo, G. 2008. Probabilistic criteria for volcano evacuation decisions. Natural Hazards 45:87-97.

\section{Supplemental Material}

\section{Supplement}

$\mathrm{R}$ code and data for fitting the integrated population model to assess population viability of the Montserrat Oriole (Ecological Archives E095-160-S1). 